\title{
Especificidad en el análisis de contenido de noticiarios de televisión locales ${ }^{T}$
}

Cecilia Cervantes Barba Departamento de Estudios de la Comunicación Social-UdeG

EL PRESENTE trabajo recoge parcialmente la experiencia de la autora en el diseño y realización del análisis de contenido de noticiarios de televisión locales. ${ }^{2}$ Se espera que un documento de este tipo sea de utilidad para estudiantes y académicos en ciencias sociales interesados en el estudio de los contenidos noticiosos que transmiten estaciones de televisión de su localidad o región. En el mismo sentido, se presupone que compartir algunas de las dificultades enfrentadas y de los avances logrados en el nivel metodológico pudieran, a mediano plazo, impulsar el trabajo en la línea investigativa que aquí nos ocupa.

La idea no es presentar un manual para la realización de análisis de noticiarios de televisión, sino exponer primero de manera general los aspectos que a nivel metodológico comparte este tipo de análisis con el tradicional de diarios, para

1 Este documento se elaboró a partir de las notas metodológicas registradas en el điario de campo de la investigación "Mediaciones organizacionales en la construcción de la realidad pública de Jalisco. El caso de los noticiarios de televisión Al tanto", que la autora desarrolla como tesis de doctorado en el programa de doctorado en ciencias sociales que ofrecen la Universidad de Guadalajara y Ciesas-Occidente. La autora del presente ensayo agradece el apoyo financiero otorgado por el Consejo Nacional para la Cultura y las Artes y el Centro Universitario de Ciencias Sociales y Humanidades de la Universidad de Guadalajara, para la realización de dicho estudio.

2 El trabajo de la autora en el ámbito del análisis de contenido se restringe al estudio de dos noticiarios producidos en Guadalajara, México. Uno de ellos, Al tanto, creado por Televisa de Occidente en 1985 , es el más visto en Guadalajara después de 24 horas, el noticiario emblema de Televisa, según muestra un estudio de Aceves (1994). El otro es Noticiario stiper 6, con una antigüedad de dos años, producido por Televisión Tapatía, una empresa de televisión de origen local, que desde hace más de 30 años compite en situaciones de desigualdad con Televisa de Occidente. Noobstante loanterior, se considera que puede ser relevante compartir los hallazgos a nivel metodológico, pues el trabajo en èsta línea es muy escaso en México y puede servir como referente para quienes se interesen por el estudio de los contenidos noticiosos de televisión. 
centrarse posteriormente en la discusión de algunos rasgos específicos que remiten a dificultades propias del análisis contenido de noticiarios de televisión. Esta tarea se considera necesaria debido a que en los textos más conocidos ${ }^{3}$ sobre metodología de análisis de contenido, buena parte de las referencias y ejemplos concretos de estudios desarrollados, sobre todo en otros países, se refieren al análisis de prensa. En el caso de México, la situación es similar. La mayoría de los estudios se orientan hacia el análisis de la prensa nacional o local y es reciente el interés por los medios electrónicos y, en general, por enriquecer el método de análisis de contenido, como se explica enseguida.

\section{Los estudios sobre análisis de contenido en México}

El análisis de contenido constituyó en nuestro país la puerta de entrada para la realización de estudios empíricos sobre prensa, cómo registra Fuentes (1987: 28) en sus indagaciones sobre el desarrollo de la investigación de la comunicación en México. De acuerdo con lo asentado por dicho autor, los trabajos en la línea de análisis de contenido de diarios mexicanos se inician a principios de lós sesenta con los textos de Merrill $(1962,1963)$ publicados en Estados Unidos. A partir de entonces el avance en esta línea de investigación fue limitado y escaso, tal vez por las razones que el propio Fuentes expone en otro texto relativo también a la investigación de la comunicación en nuestro país:

Podemos inferir la presencia de un componente cultural muy fuerte, en el sentido de que observamos la operación social de minimización de la investigación empírica como respuesta a las creencias y representaciones sociales más ampliamente difundidas, las cuales, no obstante, están cambiando en razón de la crisis que actualmente atraviesan las ciencia sociales. Pero esto no bastaría para explicar nuestros resultados. Es evidente que cualquier clase de trabajo de campo (especialmente las más elaboradas técnicamente, como las encuestas por muestreo), representa una especie muy cara de investigación empírica. Y en México no se ha superado una situación de "ciencia pobre". Por ello, la explicación completa de la escasa producción de investigaciones empíricas de campo sobre la comunicación en México debe incluir la interacción de variables como el componente cultural (sesgo antiempirista) y las condiciones institucionales en que trabajan los investigadores (falta de financiamiento, infraestructura, recursos humanos adecuados) (Fuentes 1991: 44).

3 Por ejemplo los de Berelson (1952), Weber (1990) y Krippendorff (1990). 
La explicación de Fuentes sobre los factores socioculturales que influyen en la manera como se avanza en el campo de la investigación de la comunicación en México se vincula directamente con tres cuestiones fundamentales que nos permiten aproximarnos a la comprensión del proceso de desarrollo de los estudios en la línea del análisis de contenido. Una es la que ya se mencionó, y se refiere a que probablemente la actitud antiempirista que predominó durante un tiempo en el campo frenó el desarrollo de los estudios en el ámbito que nos ocupa. Otra tiene que ver con la identificación de un cambio en dicha actitud, debido sobre todo a la crisis en las ciencias sociales y a la búsqueda de alternativas teórico-metodológicas. Esto coincide con el resurgimiento e impulso que recibe el análisis de contenido hacia la década de los ochenta.

Si bien antes de ese tiempo se realizaron trabajos significativos, ${ }^{4}$ el avance más claro en esta línea tiene lugar cuando algunos investigadores orientan su práctica hacia el análisis de contenido, por periodos que pueden ir de dos a ocho años; tiempo que les permite realizar varios trabajos, e inclusive perfilar un programa de investigación. Tal es el caso de Arredondo (1989, 1990, 1991a y 1991b), Arredondo y Zermeño (1985 y 1986), Fregoso (1989a, 1989b, 1989c, 1990, 1991a 1991b, 1992 y 1993) Fregoso y Sánchez (1993), González (1982, 1985, 1986 y 1989), Lozano (1988, 1989, 1990, 1993 y 1994) y Cervantes (1994a, 1994b y 1995b). ${ }^{5}$

Aun cuando se trata de casos más o menos aislados en los que los investigadores no parecen haberse dedicado de manera directa àl análisis de contenido, o por lo menos no publicaron todo lo que desarrollaron, es pertinente mencionar trabajos importantes como los de Eliaschev (1982), Toussaint y otros (1986), Gutiérrez y Lobato (1989), Bailey (1989) y Acle (1990). En un texto previo de Cervantes(1994b), se registran otros estudios realizados a partir de los. ochenta, bajo la modalidad de tesis de licenciatura.

La última cuestión tiene que ver con las dificultades económicas que efectivamente enfrentan los estudiantes e investigadores interesados en la realización de estudios empíricos y, concretamente, de análisis de contenido, situación que pudo

4 Entre las investigaciones que recuperan - antes de los ochenta - de manera directa la metodología del análisis de contenido, pueden mencionarse las siguientes: Rota (1970), Moreno (1970), Sánchez (1973), Durán (1974), Maciel (1974), Sewell (1975), Aguilar (1977), Benet (1979), Ostos (1979), Portos (1979), Uruchurtu (1979) y Zermeño (1979).

5 De los investigadores mencionados, solamente Lozano y Cervantes desarrollan actualmente trabajos vinculados con el análisis de contenido. 
influir también en el avance lento del trabajo en esta línea. Este factor es fundamental en el caso del análisis de noticiarios en medios electrónicos. Retomaremos este punto cuando se inicie la exposición sobre algunos rasgos específicos del análisis de contenido de noticiarios de televisión.

\section{Lo común: diseño general del proyecto de investigación}

Al igual otras investigaciones en ciencias sociales desarrolladas sobre la base de métodos cuantitativos, los estudios sustentados en el análisis de contenido deben desarrollarse conforme a un diseño riguroso y pertinente que cuide aspectos tales como la vinculación entre supuestos, preguntas, hipótesis, perspectiva conceptual e instrumentos metodológicos que orientan el proyecto. Dado que el análisis de contenido "es una técnica de investigación destinada a formular, a partir de ciertos datos, inferencias reproducibles y válidas que puedan aplicarse a su contexto" (Krippendorff 1990: 28), es necesario que se ciña a los requerimientos de validez y confiabilidad que exige esta herramienta, pero sobre todo que se vincule con un marco de referencia conceptual claro y pertinente.

Como enfoques teóricos "compatibles" con el análisis de contenido, Lozano (1994: 143) propone los siguientes: 1) perspectiva positivista: análisis de cultivo (cultivation analysis), establecimiento de agenda (agenda setting) y sociología de medios (media sociology); 2) perspectiva crítica: imperialismo cultural, economía política y sociología de la producción de noticias (newsmaking), ésta última vinculada con la sociología de medios, y 3) perspectiva culturalista: análisis semiológicos y semióticos. Dependiendo de la pregunta central de investigación, cada estudiante o investigador determina el tipo de enfoque teórico y la herramienta metodológica pertinentes para el desarrollo de la investigación.

En el nivel del diseño, los mismos pasos pueden seguirse para la definición de un proyecto de análisis de contenido de mensajes provenientes de prensa o de medios electrónicos. Para ello pueden consultarse las propuestas de Krippendorff (1990), Weber (1990) y Lozano (1994), en las que se hace referencia, a veces de manera general y en otras de forma más específica, a cuestiones tales como: familiarización con el material empírico, fundamentación conceptual, determinación de unidades de análisis, definición de categorías, variables e indicadores, 
establecimiento del tamaño de la muestra, diseño de instrumentos para registro (hoja y manual de codificación), validación de los instrumentos (prueba de confiabilidad), capacitación de codificadores y capturistas, determinación de técnicas de análisis de la información, interpretación de resultados y elaboración del reporte final.

Si bien el análisis de contenido se emplea comúnmente para el estudio de los mensajes manifiestos, con lo que se obtienen en buena medida descripciones sistemáticas del contenido, existen alternativas interesantes para acercarse a la dimensión cualitativa de los mensajes, utilizando el análisis de contenido en vinculación con otras herramientas; por ejemplo, con el análisis de contenidos latentes (valores noticiosos) y semantizaciones (González Molina, 1986), de métodos etnográficos, especialmente observación participante, entrevistas semiestructuradas y entrevistas a profundidad (González Molina, 1989; Cervantes Barba, 1993 y 1994a).

Las posibilidades de enriquecimiento del análisis de contenido son variadas y constituyen un reto a nivel metodológico. Sin embargo, para no tratar de abarcar mucho por el momento y cumplir con el propósito de este trabajo, se han tomado en cuenta únicamente aquellos aspectos más generales; esto es, los indicadores que comúnmente sustentan estudios tradicionales de corte cuantitativo - duración, contador, origen, temática, etcétera - que son también los que frecuentemente aparecen como base o punto de partida, para ser complementados con categorías o modelos de análisis de tipo cualitativo. Corresponderá entonces a cada estudiante o investigador adaptar el instrumento para incluir categorías que se articulen a las que aparezcan tanto en su modelo de análisis del discurso como en la guía para la realización de observación participante, o en su guión de entrevista semiestructurada, entre otras herramientas cualitativas que pueden articularse con el análisis de contenido tradicional. ${ }^{6}$

6 Sibien aquíse coincide con Krippendorff (1990) en que el análisis de contenido que tradicionalmente ha sido considerado cuantitativo, es también cualitativo, por los agregados que ha recibido a través de la utilización del método por más de seis décadas en distintos espacios disciplinarios. Se apoya también la idea de que para ciertos estudios es posible enriquecer el análisis de contenido a través de su vinculación con métodos explícitamente cualitativos. Es por ello que en este trabajo se mantiene una cierta distinción ent re lo cuantitativoy locualitativo, con la finalidad única de destacar quẹ la dimensión cualitativa del análisis de contenido puede alcanzar distintos niveles y, en general, requiere de un diseño distinto al tradicional, en el que explícitamente se trabaje la vinculación entre aspectos cuantitativos y cualitativos. 


\section{Especificidad: la adaptación del género al medio}

El punto de partida fundamental para acercarse al análisis de noticiarios de televisión es familiarizarse con el género y con el medio. Existe una gran cantidad de textos referidos al género informativoy, por separado, otros sobre la "naturaleza" del medio televisivo. Es necesario entonces que cada estudiante o investigador realice una síntesis para tratar de entender la forma como el género, que se inició en el periodismo escrito, se ha transformado a través de su utilización en los noticiarios de televisión.

Una buena parte de las dificultades que se enfrentan al realizar análisis de contenido de noticiarios de televisión tiene que ver con las restricciones que impone el medio (a nivel tecnológico y de rutinas de producción) y con la forma como algunos aspectos del género (noticia) y de las ideologías profesionales del periodismo (objetividad, valores noticiosos) se "objetivizan" en el formato y estructura de noticiarios y notas informativas. Estos puntos se irán aclarando conforme se avance en la descripción de las especificidades (dificultades, requerimientos, posibilidades) del análisis de contenido de noticiarios de televisión.

\section{Algunos requerimientos básicos}

Frente al análisis de contenido de prensa, el estudio del contenido noticioso transmitido por medios electrónicos presenta varias desventajas que los interesados deben tomar en cuenta antes de decidirse a realizar este tipo de trabajo. Si bien este punto y el que sigue no tienen que ver propiamente con las dificultades que presenta el acercamiento al género noticioso adaptado a la televisión, es necesario referirse a ellos pues una apropiada identificación de los obstáculos en ese nivel permite planear y agilizar enormemente el trabajo, garantizando en buena medida el que se concluyan las investigaciones.

Después de esta breve justificación sobre la necesidad de incluir este apartado, inicia enseguida la referencia de algunos aspectos vinculados con el equipo técnico y humano. En el análisis de noticiarios de televisión se reproduce una tendencia generalizada en el análisis de prensa, que tiene que ver con que una buena parte de los estudios son de tipo comparativo. Esto implica que se graben y analicen varios noticiarios emitidos por diversos canales y se requiera por tanto contar con un cierto equipamiento en televisores y videograbadoras. Debido a los niveles de 
competencia que existen entre las empresas de televisión y a la concepción que tienen en torno de los mejores tiempos para emitir noticiarios, es común que la transmisión de dichos programas se realice más o menos a la misma hora. Si esto sucede, se requiere entonces de un mayor número de equipos para garantizar la grabación de la muestra requerida.

Los televisores pueden ser en general de cualquier tipo o clase. Lo que hay que cuidar es que permanentemente se reciba una señal clara, tanto en video como en audio. En el caso de las videograbadoras, es preferible que no se escatime en calidad, pues el uso puede llegar a ser excesivo. Se requerirá adelantar y regresar las videocintas varias veces, sobre todo cuando se analizan video y audio conjuntamente. Es preferible que se invierta un poco más, pero que se adquiera equipo de calidad para, por un lado, evitar el uso poco recomendable de aparatos utilizados para adelantar o regresar cintasy, por el otro, contar con la posibilidad de programar la grabación de por lo menos ocho programas. Esto es de gran utilidad aún en los casos en que los asistentes pudieran grabar los noticiarios en el momento de su transmisión.

Si no se cuenta con el equipo necesario, se requiere adquirirlo o solicitarlo en préstamo durante el periodo que duren las grabaciones. Del mismo modo, es necesario adquirir videocintas de calidad aceptable, pues debe reducirse el riesgo de que se rompan o deterioren por el manejo que reciben. Se recomienda adquirir cintas de 120 minutos, que grabadas en extended play permiten contar con seis horas, y así grabar en una sola videocinta todos los noticiarios de un día, o de varios días, dependiendo de la muestra. A menos que sean de muy buena calidad, las videocintas de 180 minutos introducen mayores riesgos por el tipo de manejo que normalmente reciben.

El último requerimiento lo constituyen los cronómetros. Es mejor contar con los de tipo profesional, utilizados, por ejemplo, por deportistas. Aunque es más económico adquirir relojes de mano con cronómetro, su tamaño los hace difíciles de manejar, no permiten la concentración que requiere el registro de datos y, en general, dificultan las tareas.

Además del equipo de grabación se requiere equipo de cómputo - y softwarepara la captura, manejoy análisis de datos. El mínimo necesarioes una computadora 
que cuente con programas compatibles de procesamiento de textos y de datos - hoja de cálculo. ${ }^{7}$

Otro aspecto fundamental para lograr un mayor avance en este tipo de trabajos y presentar los resultados más rápidos ${ }^{8}$ es el relativo al número de asistentes con el que es conveniente contar. En general es deseable contar con un equipo mínimo de tres asistentes. Dos pueden realizar las tareas de registro de datos en las hojas de codificación - medir tiempos y vaciar información relativa a fuentes, origen y temática - y el otro fungir como responsable de etiquetar y almacenar las videocintas, de registrar salidas y devoluciones de las mismas, de capturar en hojas de cálculo los datos que los otros dos asistentes registraron en las hojas de codificación y de encuadernar y almacenar las hojas de codificación.

$\mathrm{Al}$ responsable de la investigación le corresponderá diseñar los instrumentos, probarlos, integrar la base de datos para la captura de la información registrada en las hojas de codificación y realizar el análisis de la información. En el caso de que varios estudiantes sean los responsables del trabajo, se requerirá entonces que diseñen el estudio en conjunto y se distribuyan las tareas mencionadas.

El tamaño del equipo de trabajo puede crecer en función de la complejidad del estudio. Para definir el número de personas que se requiere, es necesario tomar en cuenta que un noticiario de media hora, con una hoja de codificación que contenga alrededor de quince items, se analiza en aproximadamente 60 ó 70 minutos. La captura de las hojas de codificación procedentes de un noticiario como el mencionado, requiere de 40 ó 50 minutos, dependiendo de la destreza de quien realiza la tarea y del número de notas.

Con estos datos, cada responsable de proyecto contará con un parámetrogeneral que puede ser útil para planear, dependiendo del número de noticiarios y de su

7 Por la experiencia de trabajo, la autora del presente ensayo recomienda el paquete de software Microsoft Office, que cuenta con los programas Word, para procesamiento de textos, y Excel, como hoja electrónica de cálculo. Se recomienda la utilización de estos programas de cómputo porque facilitan la tarea de captura y el manejo de datos, además de que son muy útiles para la integración de avances de investigación y del reporte final.

8 Se insiste aquí en la optimización de recursos y tiempo, debido a que buena parte de los estudios realizados en esta línea se orienta hacia el análisis coyuntural o de eventos extraordinarios que afectan la vida social, tales como desastres, corrupción gubernamental y elecciones, entre otros, y se requiere por tanto que el trabajo se dé a conocer lo más pronto posible. Puede ser también que los estudios se realicen con el financiamiento de organismos o instituciones que soliciten monitoreos o diagnósticos a corto plazo, por loque la planeación y uso adecuado de los recursos es indispensable para cumplir con lo programado. 
duración, la cantidad de personas que habrán de desarrollar las tareas a que se ha hecho referencia.

\section{Para agilizar las mediciones}

Un aspecto básico en el análisis de mensajes noticiosos producidos por los medios en general, es el que tiene que ver con la medición, esto es, con la superficie (centímetros cuadrados) que los diarios o el tiempo (segundos) que los noticiarios de radio y televisión dedican a las notas. En el caso de la televisión, se requiere comúnmente la medición de cabezas, notas, pie y fin de notas, editorializaciones, referencias a actores, declaraciones realizadas por actores e imágenes en que aparecen actores y acontecimientos, entre otras. Del mismo modo se ubica en este nivel el registro del contador. En un diario esto equivale a identificar en qué página aparece cada nota. Para el caso de los noticiarios de televisión, se anota el segundo en que inicia cada nota, sobre la base de una cuenta progresiva.

Tal vez uno de los aspectos que requieren mayor detalle y concentración es el de las mediciones que se fijaron como pertinentes para el análisis. Por este motivo, si una sola persona realiza el trabajo, se recomienda que primero registre todas las mediciones y luego los otros indicadores que aparezcan en la hoja de codificación. Si se llega a adquirir suficiente destreza es posible medir la duración de manera simultánea al registro de otros aspectos del contenido. Sin embargo, lo más probable esque todas las mediciones se realicen en una etapa y, posteriormente, se lleve a cabo el registro de otros datos necesarios para el análisis, tales como fuentes, origen, actores, temática, entre otros.

Elavance es mayor si se trabaja en parejas. De esta manera, una persona auxiliada por el cronómetro de mano puede realizar las mediciones generales - cabezas, notas y publicidad - y tomar notas sobre algunos otros aspectos indicados para el análisis, en tanto que la otra registra el contador, valiéndose para ello del cronómetro integrado con que cuenta la videograbadora y registra datos del contenido distintos a los que asienta el otro codificador. Esta es la forma como generalmente se avanza más y puede obtenerse un mayor control y retroalimentación, pues aun cuando previo al inicio del registro se haya realizado la prueba de confiabilidad de los instrumentos (hoja y manual de codificación), es probable que surjan dudas o que aparezcan modalidades en el contenido, que no se presentaron durante la prueba y, trabajando en parejas, los codificadores pueden auxiliarse. 


\section{Ajustes en el proceso de codificación}

El papel que las categorías tienen en el análisis de contenido es fundamental, por lo que deben definirse de manera precisa para garantizar un adecuado proceso de codificación. El responsable del proyecto realiza por lo menos un doble acercamiento con las categorías. Por un lado, le corresponde desarrollar la tarea compleja de definición de las categorías y, por el otro, de identificar y registrar los indicadores que remiten a las categorías. Cuando se trabaja en equipo, es generalmente el responsable de la investigación quien determina, sobre la base de las preguntas de investigación, las hipótesis y la perspectiva conceptual, las categorías que servirán como eje para el análisis. Por su parte, los asistentes se habilitan en la identificación de los indicadores ligados a las categorías establecidas para el desarrollo del proyecto, y los registran en la hoja de codificación.

Uno de los mecanismos para lograr que todos los participantes en el proyecto compartan una concepción similar de las categorías, los temas y subtemas, es la prueba de codificación. ${ }^{9}$ Sin embargo, los alcances de dicho instrumento son limitados, pues aun cuando se obtenga un alto porcentaje de confiabilidad a través de la realización de la prueba, las dudas generalmente persisten. Es frecuente que aún después de varias semanas de iniciado el análisis, surjan nuevas preguntas o exista confusión.

Este problema es tal vez mayor en el caso de los noticiarios de televisión pues, a diferencia de los diarios, es más difícil, por ejemplo, revisar todas las notas que constituyen la muestra para tener desde el principio una idea general de las categorías que serían más pertinentes de acuerdo con la perspectiva conceptual y con los objetivos de la investigación. Dado que resulta poco práctico revisar todos los noticiarios antes de iniciar el análisis, se sugieren aquí algunas alternativas para avanzar de mejor manera en este tipo de trabajo.

A partir de la revisión de una parte de los noticiarios y del conocimiento previo de los mismos que generalmente tiene quien plantea el proyecto, es posible elaborar una primera tipología de categorías y definir los indicadores que remiten a cada una de ellas. Generalmente, es sobre la base de este trabajo inicial que se definen la hoja y el manual de codificación y se realiza la prueba piloto. Si el grado de

9 Los textos de Krippendorff (1990) y Lozano (1994) remiten al procedimiento que generalmente se sigue en el diseño y realización de la prueba de confiabilidad. 
confiabilidad de la misma es mayor de 85 por ciento, como sugiere Lozano (1994), es posible proceder a realizar el análisis.

Es conveniente que el responsable del proyecto no participe en la prueba y que, de ser posible, realice una prueba con quienes constituirán el equipo de codificadores y otra con un grupo ajeno al proyecto; por ejemplo, con otros estudiantes o investigadores ubicados dentro del ámbito de las ciencias sociales. La realización de dos pruebas resulta generalmente muy benéfica para la depuración de instrumentos. Sin embargó, en el caso de los noticiarios de televisión es muy probable que se requiera todavía un trabajo adicional, que consiste en que por lo menos durante las primeras sesiones de registro, el responsable se encuentre presente mientras los asistentes realizan la codificación, sin que intervenga directamente en el registro. Esto permite aclarar dudas y precisar criterios en equipo.

Buena parte de las dificultades que se presentan en la homogeneización de criterios para codificar proceden de la dificultad de incluir desde el principio en el manual de codificación la mayoría de temas y subtemas que pudieran aparecer en los noticiarios. Se elabora generalmente un listado inicial, pero una vez iniciado el análisis aparecen inevitablemente otros temas y subtemas y es común que se realicen sesiones especiales para llegar a acuerdos sobre la manera como se integrarán los nuevos temas y subtemas. Puede ocurrir inclusive que se modifique la hoja de codificación y sea necesario regresar a los noticiarios que ya se habían analizado, para completar el registro con las categorías, temas o subtemas que hayan surgido.

El análisis de noticiarios de televisión implica que la definición de las categorías y de las tipologías de temas y subtemas no se pueda anticipar completamente desde el principio. Esto es algo que el investigador o estudiante debe tener en cuenta y estar muy atento durante las primeras semanas de codificación.

\section{¿Desdibujamiento de la geografía en las notas?}

Dos categorías básicas en el análisis de diarios son la procedencia u origen de la nota y el lugar de referencia. La primera se refiere al lugar donde se origina la nota y la segunda al lugar o lugares que se mencionan en el contenido de la nota. Es así que una nota puede originarse en la ciudad de Monterrey y referirse a todo el país en general, o a los estados del norte. Se supone que el análisis de estos datos permite integrar un mapa de los lugares que los productores del noticiario o las fuentes 
consideran relevantes y se integra de ese modo el análisis de la "geografía" de los acontecimientos; esto es, de los lugares donde surge lo noticiable.

En el caso de las notas de televisión locales, un rasgo fundamental es que prácticamente no aparece en ninguna nota la procedencia u origen de la misma y, de manera muy limitada, se presentan datos sobre el lugar de referencia. Con excepción de las notas policiacas, prácticamente el resto de la información no proporciona explícitamente los datos mencionados. El codificador pudiera deducir dónde se originó la nota, por las imágenes de los lugares o por los personajes involucrados en el evento acontecimiento. Sin embargo, basar el análisis en ese tipo de "extracciones" de datos no es confiable ni se recomienda hacerlo .Lo más indicado es anotar "dato no especificado" y considerar este indicador como un aspecto fundamental para la interpretación.

Este rasgo de los noticiarios de televisión se deriva en parte del tipo de noticiario de que se trata, del formato de las notas y de los patrones de cobertura que rigen en la televisión. Es así que, además de tomar en cuenta que el investigador o estudiante trabaja con noticiarios locales aparentemente muy familiares a la audiencia en el nivel del contenido, se enfrenta con que el material a analizar puede ser afectado por otros rasgos del género y de la práctica periodística, tales como una fuerte tendencia al "periodismo de declaraciones"; esto es, a cubrir lo que las fuentes oficiales o personajes con presencia pública tienen que decir cotidianamente o en coyunturas específicas. Estos aspectos tienen que ver de alguna manera con la definición de formatos para las notas de televisión y con el hecho de que no necesariamente incluyan la mención al lugar donde se origina la información y muy pocas veces la referencia a otros lugares. A continuación se presentan tres ejemplos:

\section{Nota 1}

Presentador: "Con Tratado de Libre Comercioo sin él, México marchabien, reiteran los industriales".

Reportera: "Convencidos de que no habrá lamentaciones por la no aplicación del Tratado de Libre Comercio, los industriales reiteran una vez más que, con o sin TLC el país sigue adelante, y bien; incluso, hasta resulta más atractivo a la inversión foránea que nuestro vecino del norte".

Entrevistado (Sergio García de Alba, industrial): "Somos de los países con menor relación de deuda, este, a producto interno bruto, este. Hay países que tienen de 120 a 140 por ciento del PIB como deuda. México está como en 25 por ciento. Creo 
que fue el último dato que se dio, este, y como les digo, hay una plataforma que a veces los mismos mexicanos no la, no la.observamos, y resulta que tienen que venir empresarios de Europa, que tienen un entorno diferente".

Reportera: "García de Alba Zepeda señaló por otro lado, que ante la competencia desleal que representa la importación de productos terminados contra los hechos en México a precios más bajos, se deben cerrar candados y normar con aranceles los que resulten fuera. Los presidentes de la Cámara Regional de la Industria de lạ Transformación de Jalisco y de la Cámara de Comercio de Guadalajara firmaron convenios de colaboración entre ambas instituciones del sector privado. Uno se refiere a la búsqueda de proyectos de colaboración entre las secciones especializadas, complementarias entre sí, las productoras y las otras comercializadoras. Los comerciantes tapatíos se comprometen a dar preferencia a los productos nacionales, ya que la importación genera fuentes laborales y divisas para el extranjero. Sergio García de Alba explicó que los industriales deben mejorar en tres aspectos: presentación y empaque, eficiencia en tiempos de entrega e implementación del código de barras" (Noticiario Al tanto, 10 de noviembre de 1993).

\section{Nota 2}

Presentadora: "El gobierno del estado aún no tiene conocimiento del proyecto del parque Metropolitano. El gobernador Carlos Rivera Aceves dice que no se puede determinar sobre la posibilidad de otorgar en comodato un terreno a la Universidad Panamericana. Aclaró que el gobierno estatal no puede tomar una determinación, porque eso le compete al Congreso del Estado. El señor Rivera Aceves reiteró que desde hace dos semanas dejó ęn claro que la administración a su cargo no ha participado en las negociaciones, las cuales han sido directamente hechas por ejidatarios" (Noticiario Al tanto, 10 de noviembre de 1993).

\section{Nota 3}

Presentador: "En otro municipio, en Zapopan, el gobernador Carlos Rivera Aceves realizó una gira de trabajo, supervisó e inauguró obras por varios millones de nuevos pesos".

Reportero: "Más de 18 kilómetros de pavimentación, adoquinamiento, electrificación y alumbrado público inauguró en Zapopan el gobernador Carlos Rivera Aceves, en un recorrido en el que sí se inauguraron obras públicas y no sólo se supervisaron avances. Rivera Aceves constató junto con el alcalde de Zapopan, 
Jorge Humberto Chavira, la puesta en operación de vialidades que unen a la cabecera municipal con zonas alejadas de Zapopan; por ejemplo, en San Juan de Ocotán (...) Enseguida se visitó la obra del libramiento de la base aérea que, será una base aérea del periférico (...) En el poblado de Copala" (Noticiario Al tanto, 10 de noviembre de 1993).

En la primera nota no aparece información sobre el origen, aunque sí sobre el lugar de referencia: México, en general. Esta forma de presentación de las notas es muy común en los noticiarios locales. Tanto en las notas breves, que no incluyen declaraciones, como en las que contienen insertos los puntos de vista de los entrevistados, es común que no se especifique el lugar en el que se originó la nota; esto es, el sitio en el que se recolectó la información; inclusive que no se mencione un lugar de referencia, como sucede en el caso de la nota 2. puede deberse a que en los noticiarios locales se asume que la audiencia ubica a las instituciones o a los sujetos involucrados. Un ejemplo claro de esto es la nota 2 , en la que se dice "el gobierno del estado", sin señalar que se trata de Jalisco. Se presupone que la audiencia identifica a Carlos Rivera Aceves, a la Universidad Panamericana y al Congreso del estado, y que además tiene cierta información previa sobre el caso.

Estos aspectos son fundamentales para analizar los valores que subyacen en la producción noticiosa, por lo que no debe eliminarse la columna "origen" de la hoja de codificación sino que, por el contrario, debe considerarse la poca o nula presencia de datos sobre el origen como algo de suma importancia y registrarlo. Es necesario también asentar los casos en los que no aparece el lugar de referencia para posibles inferencias o interpretaciones que ayuden al estudiante o investigador a vincular la evidencia empírica con la argumentación general de su proyecto sustentada en un marco teórico específico, sobre todo si tiene que ver con el análisis de valores noticiosos o con el establecimiento de agenda.

En el caso de la investigación de la que aquí se da cuenta, prácticamente no se encontraron datos sobre origen y lugar de referencia en las notas de información local, con excepción de las notas policiacas. Es en éste último tipo de notas en el que con mayor frecuencia se registran las categorias mencionadas, sobre todo cuando se trata de accidentes, asesinatos, robos de importancia y suicidios. Además de la información policiaca, existen en menor grado otro tipo de notas en las que eventualmente aparecen datos sobre origen o procedencia. Se trata de notas en las que se cubren giras de funcionarios públicos de nivel federal, estatal o municipal. 
En esos casos, generalmente aparece no sólo el registro del municipio o zona donde se realizó la gira, sino las distintas áreas que se visitaron a lo largo del trayecto, como muestra la nota 3 , arriba citada.

\section{Distinción de fuentes}

En el noticiario analizado, la sección de información local ocupa buena parte del tiempo total del programa. Esto implica que prácticamente todas las notas son producto de la cobertura que realizan los reporteros y camarógrafos de la empresa y no se requieren los servicios de agencias informativas o corresponsales para la adquisición de notas. En la información local no aparece, por tanto, la referencia a fuentes. No es el caso de las notas nacionales e internacionales, en las que se utilizanimágenes que proceden de Televisa. Dadoquela empresa local que produce el noticiario $A$ l tanto es parte de Televisa (antes Telesistema Mexicano), desde la creación del mencionado programa informativo, las notas sobre otros estados y sobre el país en general proceden del material que produce ese consorcio, de tal forma que no aparecen referencias a agencias o corresponsales, sino más bien a 24 horas, el noticiario más importante de Televisa.

Es posible que en noticiarios locales producidos en otros estados del país aparezca en recuadro o en alguno de los márgenes inferiores de la pantalla la referencia a alguna agencia o corresponsal. En ese caso, es necesario considerar las fuentes en una columna especial. Si, por el contrario, sucede lo del caso del noticiario Al tanto, en el que la información local no registra el tipo de fuentes (agencias, corresponsales) que tradicionalmente aparecen en las notas de los diarios, es necesario realizar el registro de otro tipo de fuentes que es fundamental en el caso de las notas locales. Se trata de la identificación de quienes fungen como definidores primarios de la realidad; esto es, de aquellas que generan acontecimientos: ruedas de prensa, ceremonias, celebraciones y giras de trabajo; que pudieran ser las mismas a las que los reporteros recurren rutinariamente en busca de información: gobierno del estado, gobiernos municipales, sector salud o corporaciones policiacas, $o$ en coyunturas específicas. ${ }^{10}$

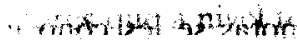

10 Un ejemplo del análisis de contenido realizado concretamente en torno de la identificación de fuentes es el que realizó Lozano (1993b) sobre la cobertura al ataque a la aduana de Nuevo Laredo en 1993. 
Para registrar este tipo de fuentes es conveniente integrar una tipología que permita distinguir sila información proviene de fuentes rutinarias o extraordinarias; esto es, de fuentes que generalmente tienen poca presencia en el noticiario, tales como organizaciones civiles emergentes, funcionarios de bajo rango o individuos a los que se entrevista por su rol como testigos, entre otras. El análisis de este aspecto del contenido informativo es muy importante, sobre todo cuando se vincula con el estudio de rutinas de selección de información que tienen lugar en la jefatura de información o en la sala de redacción. Permite conectar el análisis de las fuentes con el de la planeación de la cobertura, para identificar, entre otros aspectos, el peso que adquieren cierto tipo de definidores primarios de la realidad en la integración del contenido noticioso.

En el estudio de las fuentes, es necesario distinguir entonces entre fuentes que forman parte de la propia empresa periodística - corresponsales, reporteros de otras estaciones del consorcio o de las instalaciones centrales del consorcio - y las externas, entre las que se encuentran las agencias $u$ otro tipo de empresas que ofrecen servicios informativos, ylas instituciones, organismos, asociaciones ygrupos civiles que cotidianamente proveen a los reporteros de información para la elaboración de notas.

\section{El análisis de la "ilustración"}

En los noticiarios de televisión, las notas adquieren diversos formatos, dependiendo de los recursos con que cuente la empresa para realizar la cobertura de eventos y de la importancia que se le otorgue a éstos últimos. El análisis de dichos formatos es necesario para identificar cierto tipo de criterios que subyacen a la integración de las notas. A continuación se sugiere una tipología de análisis de formatos que se centra sobre todo en la distinción entre notas que cuentan con "ilustración" y las que carecen de ella. Al igual que los diarios que ejemplifican o refuerzan la información con fotografías, los noticiarios de televisión cuentan con recursos propios para "informar con imágenes". Es así que algunas notas incluyen "insertos", como dicen los productores de los noticiarios; esto es, presentan la grabación de declaraciones realizadas por actores involucrados en los eventos o la descripción visual de lugares o acontecimientos. A este tipo de notas se les conoce como "sonido". 
Existe otro tipo de "ilustración", que presenta solamente lä imagen del personaje declarando o del acontecimiento, pero sin voz del actor o sin sonido ambiente. El reportero relata los hechos o se refiere a las declaraciones del personaje. Las notas de este tipo reciben, por parte de los productores, el nombre de "texto".

En los noticiarios analizados se encontraron otras variaciones en el formato que no reciben denominaciones específicas ën la empresa productora de $A l$ tanto por lo que, para fines del análisis, se les otorgaron los siguientes nombres. A las notas que son relatadas por el conductor e incluyen la imagen que grabó el reportero, pero sin que aparezca éste último, se les denominó “conductor-imagen". Del mismo modo, las que son relatadas exclusivamente por el conductor y que en general duran de 10 a 15 segundos, se les llamó "conductor". Cuando la nota se transmitía en vivo, vía telefónica, se registró como "llamada". En síntesis, se integró una tipología que recuperó en parte las denominaciones utilizadas por los propios productores - a las cuales se tuvo acceso gracias al trabajo de campo realizado por la autora en la estación de televisión - pero que se complementó con otras categorías indispensables para identificar tipos de formatos que los productores no distinguen.

Cuando el estudiante o investigador no tenga acceso a la empresa productora, puede integrar su propia tipología basada en categorías descriptivas. Por ejemplo, "voz-imagen" sería el equivalente de "sonido", "reportero-imagen" de "texto", además de las otras tres categorías ya mencionadas: "conductor-imagen", "conductor" "y "llamada". Precisar las tendencias que se siguen en la "ilustración" puede ser de suma importancia para mostrar qué tipo de actores y de eventos se consideran más relevantes en el noticiario, pues se presupone que las notas de mayor importancia incluyen imagen y voz de los protagonistas, y'las que tienen menor relevancia son relatadas de manera muy breve por el conductor, sin incluir imagen ni narración de algún reportero.

Un análisis de este tipo puede corroborar lo anterior, o mostrar interesantes excepciones a la regla. Aun cuando se supone que las notas sin imagen ni voz de protagonistas o de reporteros son las que el medio considera como menos importantes, el análisis del formato que se sigue para "ilustrar" notas permite descubrir rasgos de las ideologías profesionales de los periodistas y las estrategias de los productores que a nivel teórico pueden vincularse con formas de control social. Por ejemplo, en el noticiario analizado se encontró que en las notas realizadas bajo el formato "conductor"; esto es, las más breves y sin ilustración, se utilizaban en 
una gran proporción para referirse a asuntos de gran relevancia social que de esta forma se minimizaban, tales como involucramiento del gobernador del estado en conflictos y posibles hechos de corrupción - autorización ilegal de licencias, permisos o contratos especiales - defensa del gobernador, de autoridades municipales y de miembros del Partido Revolucionario Institucional (PRI) ante ataques y manifestaciones de grupos y asociaciones civiles, entre otros. Una tipología detallada de formatos en el nivel de la "ilustración" de notas, permite identificar sutiles estrategias - no necesariamente planeadas de manera consciente - de los productores, mismas que, de no contar con una tipología fina de análisis de la "ilustración", pasarían desapercibidas. De ahí la importancia de que cada estudiante o investigador identifique y clasifique de manera detallada los diversos recursos que las empresas informativas utilizan para relatar los acontecimientos a través de formatos específicos.

\section{Editorialización}

Otro aspecto del contenido de las notas que comúnmente se registra es la editorialización. Esto implica que los codificadores deben identificar si la nota contiene cierto grado de opinión o si en la nota aparece reflejada la postura del medio frente a cierto acontecimiento o actor social. En general, se registra solamente "si" cuando la nota contiene editorialización y "no" cuando carece de ella. Este aspecto se analiza a menudo bajo el rubro "tratamiento" y se definen tres categorías: "en pro" o "a favor", "neutral" y "en contra".

Sin restarle importancia a la forma como en buena parte de este tipo de estudios se realiza el registro de la editorialización o tratamiento de la información, se propone aquí la realización de un análisis más detallado, para el caso de los noticiarios de televisión que son breves y permiten este tipo de trabajo.

Por una parte, se considera indispensable distinguir quién realiza la editorialización; esto es, identificar si el comentario o la opinión proviene del conductor, del reportero o del protagonista que realiza declaraciones. Es necesario también registrar si la editorialización tiene lugar en el pie de nota, en el relato que realiza el reportero - que puede incluir los "sonidos" con declaraciones de protagonistas $y$, por tanto, sus editorializaciones, o en el fin de nota. Del mismo modo, se recomienda medir el tiempo dedicado a editorializar. 
Para enriquecer más el análisis, es importante determinar las formas que adopta la editorialización, entre las que se encuentran el comentario, la opinión, la exhortación al juicio, la controversia y la dramatización, entre otras. Del mismo modo, se recomienda identificar tipos de editorialización. En el caso del noticiario analizado, se detectaron notas en las que aparece explícitamente la editorialización y otras en las que el reportero editorializa sin necesidad de realizar comentarios o de expresar su opinión; para ello se vale de los recursos periodísticos con que cuenta. En el primer caso se encuentra la siguiente nota, en la que abiertamente el presentador y el reportero presentan su punto de vista sobre los asuntos tratados.

\section{Nota 4}

Presentador: "Buenos días. Pues graves anomalías se están registrando en la Dirección de Seguridad Pública en el Estado. Juzgue usted los hechos".

Reportero: "Situaciones inexplicables, notoriamente irregulares y merecedoras de una investigación profunda se están dando en la Dirección de Seguridad Pública del Estado. Al menos en los últimos días han quedado al descubierto algunos detalles que podrían ser tomados como botones de muestra de la causa de inseguridad en nuestra ciudad y en el estado. El pasado sábado en la madrugada, tres individuos fueron detenidos cuando, ebrios y empistolados, dispararon contra un auto compacto, donde viajaban tres adolescentes. Uno de ellos resultó herido. El grupo de empistolados era encabezado por un joven que resultó ser el hijo del jefe del escuadrón de apoyo de la Dirección de Seguridad Pública Estatal. Esta persona portaba una pistola de grueso calibre. El lunes por la noche patrulleros de la municipal tapatía sorprenden a cinco individuos en el momento en que, con armas de alto poder, trataban de obligar a una persona a que se desistiera de una acusación en su contra. Todos fueron detenidos. Tres resultaron ser oficiales de alto rango de la Dirección de Seguridad Pública Estatal.Ellos son Emilio Villalbazo Cuevas, Félix Nájera Valentín y Raúl Sánchez Hernández. Un detalle inexplicable es que el grupo viajaba a bordo de una camioneta pickup asignada a la jefatura de la Dirección de Seguridad Pública del Estado. Este vehículo al parecer estaba siendo utilizado como mudanza, a juzgar por el mobiliario que traía en la caja, el cual no parece ser de ninguna oficina policiaca. Y una circunstancia más, que no deja de ser preocupante para la ciudadanía que reclama tranquilidad y que deja al descubierto una extraña vinculación con la delincuencia, surge con la siguiente historia. El 31 de agosto, en menos de un mes se comete el segundo asalto a la 
sucursal de Telégrafos ubicada entre las calles Honduras y Brasil, de la colonia del Sur. Tres hombres armados, además del botín se llevan la escopeta calibre 12, matrícula 12765 del policía de Seguridad Pública que cuidaba dicha oficina. Los ladrones, en su afán por escapar, tiran el arma que habían robado, la cual es recogida minutos después por patrulleros de la policía municipal. La jefatura de Seguridad Pública del estado reclama la escopeta y ésta, mediante oficio, le es remitida por el director de Seguridad Pública. Este lunes vuelve a ser asaltada la misma sucursal telegráfica por tres sujetos armados, uno de ellos con una escopeta. Se llevan entre 10 y 14 millones de viejos pesos. Al escapar hacia un taxi, uno de ellos tira la escopeta y ésta, al igual que la vez anterior, es recogida por la policía uniformada de Guadalajara, pero esta ocasión la sorpresa fue mayúscula. Se trataba de la misma escopeta del anterior asalto, con la misma matrícula, mismo calibre y, como para que no hubiera duda, traía aún una etiqueta que le habían puesto el 31 de agosto en la bodega de la policía municipal de Guadalajara".

Presentador: "Está muy difícil creer que la policía está haciendo distintos esfuerzos por moralizarse y modernizarse. Esto que nos cuenta Salvador Chávez no son hechos aislados. Claro que en un cuerpo de vigilancia, en un cuerpo de policía, se da la corrupción; desde luego que lo entendemos, máxime cuando los sueldos no son los adecuados. El otro día, platicando con el productor, decía que por lo menos se necesitaban 5 millones de pesos nuevos, perdón, de viejos pesos, tenien..., para que un policía judicial, por ejemplo, un policía municipal tuviera un sueldo digno, ganando, alrededor de uno doscientos. Sin embargo, no son hechos aislados. Se dan seguido y, bueno, esto indica claramente que la autoridad o las autoridades están pagando para tener una policía en donde la ciudadanía pueda decir con confianza que es un servidor público que vigila por su bienestar" (Noticiario $A l$ tanto, 10 de noviembre de 1993).

Se recomienda entonces no sólo registrar la editorialización que, como en la nota 4, aparece bajo la forma de comentarios u opiniones explícitos, sino también en los casos en los que el reportero - restringido por los cánones de objetividad se sirve de otros recursos para "golpear" o "exponer" a su fuente, y presionarla de 
alguna forma. ${ }^{11}$ En las siguientes notas se puede apreciar el uso de ciertos recursos narrativos.

\section{Nota 5}

Presentador: "Buenos días. Pues para comenzar le diremos que vendedores ambulantes se están negando a dejar el centro de la ciudad en la temporada navideña". Reportera: "Líderes de vendedores ambulantes de la zona centro de Guadalajara se niegan a desligarse del primer cuadro durante la temporada navideña. Esto como reacción a la medida que anunció el Ayuntamiento tapatío de que no permitirá a nadie ocupar la zona adoquinada del centro histórico".

Entrevistado: "Pues la postura de nosotros, más que nada es que se nos facilite trabajar como año con año lo hemos venido haciendo, ya que del trabajo que desempeñamos nosotros depende un promedio de cuatrocientas o quinientas gentes, o sea, cuatrocientas o quinientas familias, las cuales son personas humildes y que año con año han venido trabajando en la zona centro".

Reportera: "Dicen que tienen derecho a trabajar en esta zona porque son gente organizada que pertenece alPRI y siempre han tenido facilidades del Ayuntamiento para vender en las calles del centro. Se oponen a ser reubicados al parque Morelos, porque los del centro venden envolturas de regalo en su mayoría, y por la Calzada les quedan más lejos las tiendas. Insisten en que el Ayuntamiento rectifique su postura".

Entrevistada: "Nosotros creemos que sí debe de darse, pero en ciertas áreas, como lo ha hecho, como lo hizo la Administración pasada, que sí dio lugares más visitados. Con la gente que realmente sí trabajaba año con año, no con los que se dejan venir, que eso lo sabemos, nos invaden".

Reportera: "Sin embargo, piden que la autoridad municipal sea pareja, porque ahorita deja deambular a los vendedores de una organización nueva que, según dicen, está protegida por un alto dirigente del PRI. Se trata de gente que vendió sus espacios dentro del Mercado Corona y ahora tiene permiso para andar en las

11 En el caso del análisis que realizó la autora del presente ensayo, el trabajo de campo desarrollado durante seis meses al interior de la empresa de televisión que produce el noticiario Al tanto, permitió detectar vinculaciones y antagonismos entre algunos reporteros ysus fuentes, por lo que fue posible identificar notas con las que se trataba de afectar a la fuente utilizando ciertos recursos estilísticos. 
calles, pero también ellos se oponen a que el Ayuntamiento les impida vender en temporada navideña" (Noticiario Al tanto, 16 de noviembre de 1993).

\section{Nota 6}

Presentador: "Existe inconformidad entre los locatarios del mercado Libertad. Se quejan de la posible construcción de una rampa, porque dicen que les perjudicaría". Reportera: "Locatarios del mercado Libertad se oponen a la construcción de una rampa central, que sólo servirá para que se llene de comerciantes. Con el pretexto arquitectónico de que se utilizará para minusválidos, en el proyecto de remodelación se contempla construir una rampa que, a decir de locatarios de fonda, perjudicará sus negocios".

Entrevistado: "En realidad hay una gran incomodida (sic) porque todo este tipo de pegostes lo quieren hacer fuera de lo... de lo que se nos había dicho a nosotros. Fuera del plano de la reparación del mercadoy, como ustedes se podrán dar cuenta, todas las rampas, lo que más, lo que más hay en las rampas son comercios". Reportera: "Dijeron que lo que menos quieren son más espacios para comerciantes, los que ya se están dando con la comercialización de los nuevos locales construidos en el tercer nivel del mercado".

Entrevistado: "Es que ahorita los locales ya se cotizan a 100 millones de pesos o cantidades estratosféricas. Entonces, no quisiéramos seguir engordando el botín para algunos cuantos. Queremos deveras un mercado que tenga sus servicios".

Reportera: "Insistieron en que la mencionada rampa sólo aumentará el número de puestos y poco servirá para minusválidos o para descarga de mercancía" (Noticiario Al tanto, 16 de noviembre de 1993).

\section{Nota 7}

Presentador: "Y eso fue en el Congreso, mientras que en el Concejo tapatío, que preside Alberto Mora López, se aprobó el presupuesto de egresos para el próximo año. Es de 546 millones de nuevos pesos".

Reportera: "ElConcejo MunicipaldeGuadalajara aprobóel presupuestode egresos para el ejercicio fiscal de 1994. El monto asciende a 546 millones de nuevos pesos, cantidad que significa un aumento de 7 por ciento en relación con lo ejercido durante 1993. La mayor cantidad de dinero se destinará a sueldos; en segundo lugar, a obra pública, y en tercero, a servicios generales. En la sesión, el concejal panista Ernesto Espinoza Guarro señaló que resulta insuficiente el presupuesto 
autorizado para cubrir todas las demandas de los tapatíos en materia de servicios. Criticó la pésima distribución del ingreso a nivel nacional, que canaliza al Distrito Federal más de 80 por ciento de los impuestos que pagamos. Explicó que de cada peso que pagamos por impuestos en Jalisco, sólo 4 centavos son para los municipios. Todo lo demás lo engulle la ciudad de México. Al respecto, el alcaldc tapatío Alberto Mora López propuso realizar un análisis para enviar una iniciativa al Congreso estatal y, si se aprueba, a la Federación. Esto con el fin de solicitar un aumento a las raquíticas participaciones que destinan a los municipios".

Entrevistado: "Yo debo de entender que la propuesta en concreto que está haciendo el señor regidor se refiere a que el porcentaje que corresponda al estado de Jalisco sea elevado para que a través del mismo procedimiento, del mismo sistema, el estado de Jalisco pudiera recibir un mayor número de ingresos".

Reportera: "Morales Ortiz indicó que, debido a la insuficiencia de más dinero, para el próximo año no se pavimentarán algunas colonias que han demandado este servicio".

Entrevistado: "Bueno, ahorita nosotros tenemos el conocimiento de unas quince colonias que han hecho las peticiones a lo que es el Ayuntamiento para que, de alguna forma u otra, el Ayuntamiento contemple en su presupuesto el... la implementación de la pavimentación".

Reportero: "Por su parte, el alcalde Alberto Mora López precisó que son 76 las colonias que solicitan pavimento en sus calles. Dijo que para atenderlas se necesitarían 450 millones de nuevos pesos, casi todo el presupuesto de un año para Guadalajara. Sin embargo, señaló que se atenderán las más que se puedan con la participación de 50 por ciento de los vecinos" (Noticiario Al tanto, 10 de diciembre de 1993).

Durante el periodo analizado se detectó un patrón de fuerte editorialización en el caso de la reportera asignada a la fuente del Ayuntamiento de Guadalajara. Claras diferencias y distanciamiento entre la reportera y el presidente del Concejo Municipal se expusieron en por lo menos dos tipos de notas. El primer tipo aparece en las notas 5 y 6 , en las que, sin tratarse de demandas sociales amplias o de movimientos relevantes, se les da voz a un grupo de comerciantes ambulantes y de locatarios de mercado, que denuncian irregularidades cometidas por el Ayuntamiento, y no se presenta la contraparte; esto es, la visión del presidente o de funcionarios del Ayuntamiento. El segundo tipo de notas sigue un patrón que se 
identifica en la nota 7 con una cobertura que no respeta la tendencia generalizada en el periodismo mexicano de no tocar autoridades tales como el Presidente de la República, los gobernadores y los presidentes municipales de las principales ciudades. En la nota mencionada, aun cuando se tuvo acceso a las declaraciones del presidente, no presentan directamente sus declaraciones, sino que se parafrasean y, en cambio, se le da voz al tesorero y a la oposición - el regidor del Partido Acción Nacional.

\section{Red de temas y subtemas}

En el análisis de contenido tradicional, uno de los requisitos fundamentales es que el análisis de temas se realice conforme a categorías excluyentes. La tarea de definición de áreas temáticas no es tan sencilla como definir una cuadrícula de categorías amplias en las que sea posible incluir los temas. En las notas concretas, los temas se entrecruzan y derivan a menudo en diversos subtemas, al tiempo que se entrecruzan con temas y subtemas de otros tipos. Una alternativa para dar paso a la complejidad que presenta en este nivel la información para no empobrecer el análisis de contenido puede consistir en identificar redes de temas y subtemas o, por lo menos, diversos niveles de tematización en torno a un tema general. Para ejemplificar lo anterior, se recurre a la siguiente nota.

\section{Nota 8}

Presentadora: "El día de ayer, al filo de las cinco de la tarde, la Virgen de Zapopan fue llevada de Catedral a la explanada del Instituto Cabañas. Ahí, el arzobispo de Guadalajara Juan Sandoval presidió una concelebración y habló sobre la familia". Reportera: "La lluvia no impidió que miles de fieles acudieran a la explanada del Instituto Cabañas, en la plaza Tapatía, para participar en la eucaristía ofrecida a la Virgen de Zapopan. La manifestación de fe se hizo presente en niños, jóvenes y ancianos, algunos con lágrimas en los ojos, otros con cánticos y rezos, pero todos unidos a una sola voz implorando por el vivir de un mundo mejor. La concelebración, que duró aproximadamente dos horas, fue presidida por el arzobispo de Guadalajara Juan Sandoval Iñiguez. Durante la homilía el arzobispo exhortó a los fieles a luchar contra las amenazas que han sufrido los valores de la familia, entre ellos el aborto". 
Entrevistado: "Por eso el aborto, ese terrible cáncer moral de nuestro tiempo, crimen incalificable casi siempre oculto contra el ser humano, el más desvalido y el más inocente, debe ser absolutamente.excluido del horizonte de la vida cristiana y del matrimonio como contrario al mandato divino 'No matarás".

Reportera: "Es en el año de 1734 cuando 'La Generala' de la Arquidiócesis de Guadalajara inicia su peregrinar por todos los templos, parroquias e iglesias. Esto fue con la fe devota de que la ciudad ya no se inundara y de que la peste desapareciera. Aproximadamente fue en el año de 1840 cuando el obispo Juan Gómez de Parada convierte en tradición el regreso de la Virgen de Zapopan a sus santuario, cada 12 de octubre. Desde entonces, año con año se celebra la tradicional romería que reúne a más de un millón de fieles a lo largo de toda la travesía".

Presentadora: "En unos minutos le tendremos información sobre la celebración eucarística llevada a cabo hoy por la mañana en la Catedral metropolitana de Guadalajara, y también sobre ya... sobre el arranque de este recorrido de la Santísima Virgen de Zapopan, que fue alrededor de las 6 y media de la mañana, para llegar allá a su casa, la Basílica de Zapopan, aproximadamente a las 10 de la mañana. (Noticiario Al tanto, 12 de octubre de 1994.)

En la nota se identificaron dos series de temas:

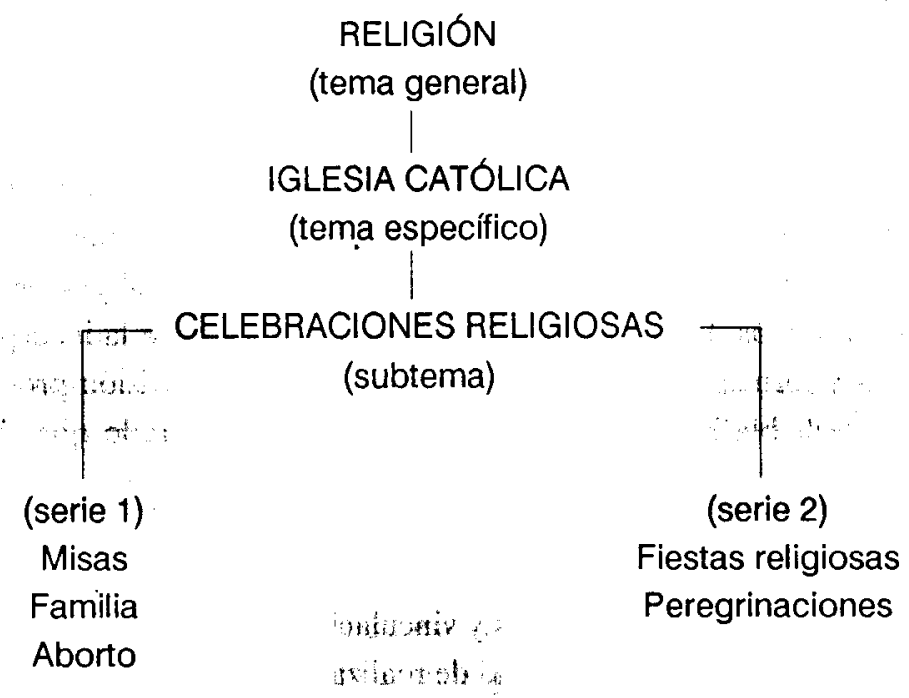


En otras notas, que ya no se incluyen en este documento por falta de espacio, aparecen vinculados dos o tres temas generales, y a partir de cada uno es posible identificar una o varias series de subtemas. En estos casos, el investigador o estudiante responsable del proyecto puede tener por lo menos tres alternativas: 1)tomar en cuenta solamente el primer tema al que se hace referencia, pues se considera que ese sería el más importante; 2)identificar el tema al que se le dedica más tiempo o en torno al cual el entrevistado realiza declaraciones, esto es, el tema que incluye "sonido", y considerar que ese es el más importante por la notoriedad del sujeto o el tipo de información que proporciona, y 3) considerar todos los temas y subtemas que aparezcan en la nota, respetando en el análisis el orden en que se presentan.

Si se elige la última opción, es necesario que la hoja de codificación contenga desde el principio un rubro que pudiera denominarse "nota multitemática", que sería distinta a la "multinota", de la cual se habla más adelante. El tratamiento de la nota multitemática debe realizarse por separado. Esto implica un subanálisis al interior del análisis de contenido general que implica el proyecto. Es así que se requiere medir la duración no de la nota completa, sino de cada tema, y registrar - si se considera pertinente - para cada tema datos como origen, lugar de referencia, protagonistas o formato utilizado en la "ilustración", entre otros.

Dado que proceder de esta forma es sumamente entretenido y complejo, es importante que antes de trabajar de esta manera se justifique el análisis de las notas multitemáticas; estoes, que exista una razón anclada en los objetivos y la orientación global del proyecto.

Por ejemplo, el análisis de las notas multitemáticas adquiere relevancia actualmente debido a que en los noticiarios mexicanos más importantes se introdujo recientemente la moda de convertir algunas notas en "historias" y extenderlas hasta seis minutos o más. Este fenómeno, que se debe en parte a la incorporación de estructuras y formas de trabajar de los noticiarios de televisión producidos por empresas de habla hispana en Estados Unidos, ha generado que en una nota aparezcan varios temas no necesariamente vinculados. Con la introducción de las historias, el análisis de la temática se complejiza, y aunque a veces es posible identificar un tema general, es difícil restringir el análisis a las tipologías tradicionales sin tomar en cuenta las redes y vinculaciones entre temas y subtemas y, a menudo, encontrarse en la necesidad de realizar análisis de notas multitemáticas. 


\section{Protagonistas}

El análisis de los actores noticiosos o protagonistas, en el caso de los noticiarios de televisión locales, puede ser más preciso si se toman en cuenta los siguientes puntos. Primero, identificar a cada uno de los protagonistas, anotando su nombre y cargo, en caso de que se trate de personas. Cuando los actores noticiosos son organizaciones o instituciones se anota el nombre tal como aparece en la nota. Después se incluye el registro de la "composición" del protagonista; esto es, si se trata de individuos, grupos formales o informales, organizaciones - con todo y su escala - instituciones - tipos - etcétera. Posteriormente conviene registrar si se le otorgó voz al protagonista, si sólo apareció su imagen o si el reportero reprodujo lo declarado por el actor.

Este punto es importante pues, aunque a nivel general se analiza primero el formato que adopta la nota en conjunto; esto es, si es "sonido", "texto", etcétera; ese registro no nos permite saber a qué actor se le otorga voz, y quienes no tienen acceso a recibir este tipo de atención por parte de los medios. Para completar el análisis, se sugiere medir el tiempo que se destina a hablar en torno a lo expresado por cada actor o a presentar sus declaraciones de manera directa.

Dependiendo del enfoque que adopte el analista, puede ser interesante analizar otros rasgos de los actores, además de la "composición". Por ejemplo: edad, género, ocupación, clase social, entre otros. Un análisis de este tipo puede arrojar datos importantés vinculables con otros aspectos del estudio.

\section{Sobre el tratamiento de la multinota}

A menudo los noticiarios locales concentran la información policiaca y deportiva en bloques de notas pequeñas. Lo relativo a deportes generalmente aparece como una sección aparte. Sin embargo, la información policiaca se presenta dentro de la sección de información local como una nota más. En el noticiario al que se refiere este análisis, la información policiaca se restringía a veces a la presentación de una nota, pero en la mayoría de los casos, adoptaba la forma de una gran nota integrada por una serie de notas breves relatadas por el mismo reportero. Por este motivo, es fundamèntal realizar el análisis de este tipo de información por separado y diseñar para ello una hoja de codificación especial. 
En la hoja de codificación que se utiliza para el análisis general de la información local, se registran los datos de la nota policiaca relativos a duración, contador, formato, origen, etcétera. De este modo, no se altera el análisis de la información local en conjunto. Por separado, en una hoja de codificación específica para la nota policiaca, se registra primero si se trata de una mononota; esto es, si con la nota sólo se cubre un asunto o evento, o si se hace referencia a varios asuntos, una multinota. A partir de ahí se registra la duración de cada nota, sea que aparezca independiente o junto con otras notas breves. Del mismo modo, se retoman las categorías que aparecen en la hoja que se diseñó para el análisis general y se aplican al análisis de notas y multinotas procedentes de la información policiaca; esto es, contador, origen, lugar de referencia, editorialización y formato, entre otras.

Procediendo de esta manera no se altera el análisis general de la información local, pues si ese análisis se desglosara, la nota policiaca que registra los datos de cada nota breve, se introduciría un sesgo en el análisis debido a que para el noticiario, la nota policiaca, aún cuando sea un resumen constituido por varias notas breves, se presenta como una nota; es elaborada por un sólo reportero y dura más o menos lo mismo que el resto de las notas de información general.

Un noticiario presenta de ocho a quince notas de información local, pero si se desglosa el contenido de la nota policiaca dentro de la misma hoja de codificación del análisis general, aumentaría a 20 ó 25 notas, lo cual constituye una diferencia importante y no refleja la estructura del noticiario. Por otra parte, si no se analizan las mononotas y multinotas por separado, se pierde la riqueza de la nota policiaca. $\mathrm{El}$ análisis específico de este tipo de información permite identificar las características de cada nota breve y la manera como se estructura la nota policiaca.

Si no se quiere elaborar una hoja de codificación específica para el análisis de la nota policiaca, existe un recurso para registrar los datos procedentes de mononotas y multinotas dentro de la hoja de codificación general. Esto puede hacerse introduciendo una clave (numeración distinta, letras) para la nota policiaca, pero si no se tiene familiaridad con el programa seleccionado para la captura y manejo estadístico de datos, es más sencillo realizar el análisis de la forma inicialmente planteada. 


\section{Recapitulación}

El análisis de noticiarios de televisión locales implica mantenerse atento a detalles que lo diferencian claramente del análisis de prensa y que permiten enriquecer los resultados de las investigaciones concretas. En cstc documcnto se hizo referencia a aquellos aspectos que permitirían en conjunto analizar una sección de información local, nacional, internacional, policiaca o deportiva, de un noticiario televisivo local. Sin embargo, dependiendo de los intereses de cada investigador o estudiante, el análisis puede centrarse solamente en uno o en varios de esos aspectos. Es posible desarrollar, por ejemplo, un trabajo en el que solamente interese la geografía de la información, y para ellose profundice en el análisis del origen ylugar de referencia de las notas. Otro tipo de estudio pudiera enfocarse a la identificación de los llamados "definidores primarios de la realidad". En tal caso, el análisis giraría fundamentalmente en torno a la planeación de la cobertura y las fuentes. Las posibilidades son variadas y los límites para cada estudio los fijan los responsables, a partir de sus preguntas de investigación, principalmente.

El interés de la autora consistió en compartir algunos hallazgos que desde el nivel metodológico permiten "dialogar" con el discurso sobre el método de análisis de contenido. El trabajo no es exhaustivo, pues existen otros aspectos del análisis de contenido de noticiarios de televisión locales, tałes como el análisis de la imagen y de secciones que vinculan información y entretenimiento, que son fundamentales para entender la forma como rutinariamente los medios construyen el acontecer público o el tipo de comportamiento que presentan en coyunturas sociales específicas.

La referencia a dichos aspectos no se incluye en este documento, pues lo que pudiera proponerse en ese sentido sería muy preliminar debido a que no se ha trabajado suficientemente ese ámbito. Por el momento, se cierra aquí esta exposición con la idea de que algunas de las sugerencias puedan ser retomadas o replanteadas por quienes consideran importante este tipo de acercamiento al estudio de los mensajes noticiosos de las televisiones locales. 


\section{Referencias bibliográficas}

ACEVES GONZÁLEZ Francisco de J. (1994): "Instantánea electoral. Guadalajara a la hora de la democracia" Renglones Núm. 29, noviembre. Guadalajara: rTESo.

ACLE TOMASINI Marcela (1990): “Análisis de contenido: problemática y perspectivas”. Revista Mexicana de Comunicación Núm. 10, marzo-abril. México: Fundación Manuel Buendía.

Aguilar Plata, Blanca (1976-1977): “Aproximación al estudio de la prensa mexicana”. Revista Mexicana de Ciencias Políticas y Sociales Núm. 23, octubremarzo. México.

ARREDONDO RAMÍREZ, Pablo (1986): "La política informativa de Televisa en los Estados Unidos: el caso de 24 horas", en Mexican Studies / Estudios mexicanos, Núm. 1, invierno. EU: University of California.

- (1989): "Los medios y las elecciones. Los noticieros de televisión y la sucesión presidencial de 1988". Ponencia presentada en el seminario "Medios, democracia, fines". México: UNAM.

(1990): "Medios de comunicación y procesos electorales. El caso de los noticieros de televisión”. Comunicación y Sociedad, Núm. 8, enero-abril. Guadalajara: CEIC-Universidad de Guadalajara.

(1991a). "Los medios de comunicación en la lucha político-electoral”. En Pablo ARredondo RAMírez, Gilberto Frego: , y Raúl TREJo DELARBRE Así se calló el sistema. Comunicación y elecciones en 1988. Guadalajara: Universidad de Guadalajara.

(1991b). “Opacidad en la ventana electrónica: el proceso electoral de 1988 en los noticieros televisivos”. En Pablo ARREDONDo RAMíREZ, Gilberto FrEGOSO y Raúl TREJO DELARBREAsí se calló el sistema. Comunicación yelecciones en 1988. Guadalajara: Universidad de Guadalajara. 
y María de Lourdes ZERMEÑo TORRES (1985): "La agenda informativa de un noticiero mexicano en los Estados Unidos (El acontecer según Televisa)". Ponencia presentada en la tercera reunión de la AMIC, México.

BAILEY John (1989): "México en los medios de comunicación estadounidenses, 1979-1986. Implicaciones sobre la relación bilateral”. E John H. COATSWORTH y Carlos Rico Imágenes de México en Estados Unidos. México: Fondo de Cultura Económica.

BENET MARSA Nuria (1979): Estudio descriptivo basado en el análisis de contenido de la comunicación científica de 1977 aparecida en ocho periódicos de cobertura nacional originados en el $D F$. Tesis de licenciatura. México: Universidad Iberoamericana.

BERELSON Bernard (1952): Content Analysis in Communications Research. New York: Free Press.

Cervantes Barba Cecilia (1994a): "Análisis de contenido y etnografía en el estudio de la producción de noticias”. En Cecilia CERVANTES BARBA y Enrique E. SÁNCHEZ RuIz (Coords.) Investigar la comunicación. Propuestas iberoamericanas. Guadalajara: ALAIC / Universidad de Guadalajara.

(1994b): "Investigación mexicana o sobre México basada en análisis de contenido. Bibliografía preliminar”. Comunicación y Sociedad Núm. 20, eneroabril. Guadalajara: DECS-Universidad de Guadalajara.

(1995): “iDe qué se constituye el hábitus en la práctica periodística”. Comtunicación y Sociedad Núm. 24, mayo-agosto. Guadalajara: DECS-Universidad de Guadalajara, Guadalajara.

___ (En prensa): "Valores noticiosos en el periodismo de nota roja. Búsqueda articulada de indicadores empíricos". Comunicación y Sociedad Núm. 25. Guadalajara: DECS-Universidad de Guadalajara. 
DURÁN SÁNCHEZ Marco Antonio (1974): Análisis de contenido de las fotonovelas impresas a colores en México, DF, en relación con la teoría de las necesidades humanas y con los estudios de psicología del mexicano. Tesis de licenciatura. México: Universidad Iberoamericana.

EliascheV José Ricardo (1982): "La abc y el enardecimiento de la prensa mexicana". Cuademos de Comunicación Núm. 85, septiembre. México.

Fregoso Peralta Gilberto (1989a): Análisis sobre información política en la prensa de Guadalajara: la sucesión presidencial. Informe de investigación. Guadalajara: CEIC-Universidad de Guadalajara.

$-r$

(1989b): "La página editorial de $E l$ Informador (Decano de la prensa jalisciense)". Comunicación y Sociedad Núm. 7. Guadalajara: CEIC-Universidad de Guadalajara.

(s. f.): Las elecciones de Jalisco y su cobertura en la prensa de Guadalajara. Informe de investigación. Guadalajara: CEIC-Universidad de Guadalajara, mimeo.

- (1990): "Las elecciones federales de 1988 en la prensa de Guadalajara". Comunicación y Sociedad No. 8, enero-abril. Guadalajara: CEIC-Universidad de Guadalajara.

(1991a): “Análisis sobre información política en la prensa de Guadalajara: la sucesión presidencial”. En Pablo ARREDONDo RAMírEZ, Gilberto FrEGoso y Raúl TREJo DELARBRE Asi se calló el sistema. Comunicación y elecciones en 1988. Guadalajara: Universidad de Guadalajara.

(1991b): "Cinco meses después...". En Pablo Arredondo RaMirez, Gilberto Fregoso y Raúl Trejo Delarbre Así se calló el sistema. Comunicación y elecciones en 1988. Guadalajara: Universidad de Guadalajara.

(1992): "La prensa regional ante los comicios de 1991". Revista Mexicana de Comunicación Núm. 23, mayo-junio. México: Fundación Manuel Buendía. 
(1993): Prensa regional y elecciones. Guadalajara. Guadalajara: CEIC-Universidad de Guadalajara.

y Enrique SÁNCHEZ RuIZ (1993): Prensa y poder en Guadalajara. Guadalajara: Universidad de Guadalajara.

FUENTES NAVARRO Raúl (1987): La investigación de comunicación en México. Sistematización documental 1956-1986. México: Edicom.

(1991): La comunidad desapercibida. Investigación e investigadores de la comunicación en México. Guadalajara: Coneicc/ ITESO.

GonZÁLEZ Molina Gabriel (1982): Radio comercial y radio cultural. Análisis ideológico de la emisión de noticias. Tesis de licenciatura. México: Universidad Iberoamericana.

(1985): iEmergencia!, 24 horas y la cobertura del terremoto en México. Colima: Mimeo.

(1986): "Valores noticiosos. La distribución desigual del acceso periodístico". Avances de Investigación Núm. 3. Colima: Universidad de Colima.

(1989): The Production of Mexican Comercial Television News: The Supremacy of Corporate Rationale. Tesis de doctorado. Inglaterra: University of Leicester.

GuTiÉRREZ EsPiNDOla José Luis y Petra LoBATo (1989): “Información radiofónica: el mundo en tres minutos". En María Antonieta REBEIL MONTOYA (et al) Perfiles del culadrante. México: Trillas.

KRIPPENDORFF Klaus (1990): Metodología de análisis de contenido. Teoría y práctica. México: Paidós.

LOZANO RENDÓN José Carlos (1988): Issues and Sources in Spanish Language TV: Comparison of Noticiero Univisión and NBCEveningNews. Austin, Texas: Mimeo. 
(1989): “Imágenes de México en la prensa norteamericana: análisis comparativo de la cobertura de México en Time y Newsweek de 1960 a 1986". Comunicación y Sociedad Núm. 7. Guadalajara: CEIC-Universidad de Guadalajara.

(1990): "Un semestre salinista en los MMC norteamericanos". Revista Mexicana de Comunicación Núm. 11. México: Fundación Manuel Buendía.

(1993a): "México y la prensa extranjera. Crisis y conflictos: estampa latente". Revista Mexicana de Comunicación Núm. 30. México: Fundación Manuel Buendía.

(1993b): "Fuentes y versiones gubernamentales en la prensa mexicana. La cobertura del ataque a la aduana de Nuevo Laredo en El Norte de Monterrey". Comunicación y Sociedad Núms. 18 y 19, mayo-diciembre. Guadalajara: CEICUniversidad de Guadalajara.

(1994): "Hacia la reconsideración del análisis de contenido en la investigación de los mensajes comunicacionales". En Cecilia CERVANTES BARBA y Enrique E. SÁNCHEZ RUIZ (Coords.) Investigar la connunicación. Propuestas iberoamericanas. Guadalajara: ALAIC/Universidad de Guadalajara.

MACIELJIMÉNEZ Martha (1974):Análisis de contenido del audio en la programación cómica de la televisión mexicana desde el punto de vista legal, utilizando como base la Ley Federal de Radio y Televisión. Tesis de licenciatura. México: Universidad Iberoamericana.

MERRILL John Calhoun (1962): "The Image of the United States in ten Mexican Dalies". Joumalism Quaterly Vol. 39, Núm 2, primavera. s. 1. i.

(1963): "The American as seen by Mexican Journalists". Latinamerican Monographs Núm. 23. Gainesville, Florida. 
MORENO PÉreZ María Concepción (1970): Estudio del contenido informativo de cincodiarios del estado de Veracruz. Tesis de licenciatura. Veracruz: Universidad Veracruzana.

PORTOS Silva Carlos (1979): La noticia de la huelga del Hospital General de la SSA en siete diarios de la ciudad de México. Tesis de licenciatura. México: Escuela de periodismo "Carlos Septién García".

OSTOS ABRÉU Margarita (1979): Análisis de contenido y estructura de los noticiarios de radio en Veracniz. Tesis de licenciatura. Veracruz: Universidad Iberoamericana.

RoTA Josep (1970): Estudio comparativo de cinco periódicos de la ciudad de México segín su morfologia, origen de la infomación y análisis de contenido. Tesis de licenciatura. México: Universidad Iberoamericana.

SÁNCHEZ MEDINA Gilda (1973): Análisis comparativo del comunicado conjunto y de algunos discursos pronunciados por el presidente Echeverría en la ciudad de México con el tratamiento dado a dichos mensajes porla televisión norteamericana durante la visita de estado de 1972. Tesis de licenciatura. México: Universidad Iberoamericana.

SEWELl Michael (1975): A Stidy of Urban Problem Treatmen in the Mexican Press: The Impact of Intemational News Diffusion of National Development. Tesis de doctorado. Austin, Texas: University of Texas at Austin.

TouSSAINT Florence et al (1986): "México en la prensa internacional". Cuadenos del Centro de Estudios de la Comunicación Núm. 9. México: FCPS-UNAM.

URUCHURTU SuÁrEZ Patricia del C. (1979): Análisis de contenido de los discursos del Lic. José López Portillo expresados durante su campaña política con el objeto de analizar su pensamiento y postura, los temas que trató y las audiencias a las que se dirigió. Tesis de licenciatura. México: Universidad Iberoamericana.

WEBER Paul R. (1990): Basic Content Analysis. Newbury Park: Säge. 
112 Especificidad en el análisis de contenido de noticiarios de televisión locales

ZERMEÑo POHLS Enrique (1979): Siete días en la prensa de León, Guanajuato: estudio descriptivo-comparativo de tres diarios matutinos segín su morfología, origen de las informaciones y análisis de contenido. Tesis de licenciatura. León, Guanajuato: Universidad de Bajío. 